\title{
EDITORIAL
}

\section{Vaping-associated lung illnesses highlight risks to all users of electronic cigarettes}

\author{
Matthew B. Stanbrook MD PhD
}

— Cite as: CMAJ 2019 December 2;191:E1319-20. doi: 10.1503/cmaj.191503; early-released November 21, 2019

CMAJ Podcasts: author interview at https://soundcloud.com/cmajpodcasts/191503-edit

See related article at www.cmaj.ca/lookup/doi/10.1503/cmaj.191402

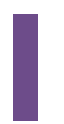

$\mathrm{n}$ this issue of CMAJ, Landman and colleagues provide a detailed report of a Canadian patient who developed a unique pattern of severe respiratory illness associated with electronic cigarette (e-cigarette) use. ${ }^{1}$ When e-cigarettes first appeared in Canada a decade ago, many - including $C M \mathrm{~J}^{2,3}-$ warned of their potential harms and called for tight regulation of their sale and marketing, as well as research sufficient to ensure product safety. Unfortunately, this never happened. In May 2018, federal legislation made legal what was already a thriving illegal market in nicotine-containing e-cigarettes. In October 2019, the sale of cannabis-containing e-cigarettes - also already being used by many Canadians - became legal as well.

The potential for e-cigarettes to harm users became undeniably real this past summer with the recognition of a North American epidemic of e-cigarette, or vaping, product use-associated lung injury (EVALI). The epidemic is ongoing, with more than 1800 patients having been ill - most of them critically - and at least 37 having died. Most patients were younger than 35 years, and $14 \%$ were under the age of $18 .{ }^{4}$ Although nearly all those affected had inhaled cannabis-containing e-liquids, most also used nicotine-containing e-liquids, and no single causative agent has yet been identified. In recent weeks, a handful of definite or possible cases have been reported in Canada. ${ }^{5}$

Although the case reported by Landman and colleagues shares many features with those described so far in the EVALI epidemic, several differences make the case unique and salient. The clinical features indicate a form of bronchiolitis - possibly bronchiolitis obliterans, a pathology not previously described with e-cigarette use, but long considered to be a likely consequence. Most e-cigarette liquids contain or generate the flavouring compound diacetyl. Diacetyl is a known cause of bronchiolitis obliterans, an association first described among workers in a factory making butter-flavoured popcorn ("popcorn worker's lung"). ${ }^{6}$ This case therefore may represent the first direct evidence of the lung disease most expected to result from e-cigarette use.

The other published reports of respiratory illnesses associated with e-cigarette use comprehensively summarized by Landman and colleagues illustrate that e-cigarettes appear to cause a wide variety of different lung pathologies and clinical illnesses. It is therefore very unlikely that any single compound, contaminant or e-liquid brand is responsible for all of them. This suggests that e-cigarette use will continue to pose important risks for lung disease even if a specific cause for EVALI is identified.

These cases have occurred because of the near-complete absence of government regulations on the composition, quality, design and manufacture of e-cigarettes and e-liquids. Although many flavouring compounds in e-liquids have never even been tested for safety via the inhaled route, enough is known about ubiquitous ingredients such as propylene glycol to indicate that all e-cigarettes contain or generate known toxins and carcinogens. ${ }^{7}$ Despite this, Canada has allowed e-cigarettes to be sold and advertised. And despite an ongoing epidemic of severe disease associated with cannabis-containing e-cigarettes, the federal government has legalized them.

The e-cigarette industry has raced to distance itself from EVALI, blaming it (in advance of conclusive evidence) on illegal cannabis products - as if it bears no responsibility for popularizing this novel mode of drug inhalation - while seeking to reassure consumers that they will be okay if they stick to well-known e-cigarette brands. ${ }^{8}$ Yet JUUL, the market-leading e-cigarette brand, was recently sued by a whistleblower who claimed that JUUL knowingly sold contaminated, nearly expired e-liquid pods and that it misrepresented the nicotine content of its products. ${ }^{9}$ The US government has also taken action against JUUL for marketing that has lured youth to its products and for illegal health claims regarding harm reduction. ${ }^{10}$ In response, JUUL has pulled its ads and many of its products from the US market - but not from Canada. In contrast, Health Canada has been reported to be considering allowing e-cigarette companies to make these same harm-reduction claims. ${ }^{11}$

The logical and responsible action to take against toxic, harmful products is to recall and ban them. As physicians, researchers and public health advocates, we must stop letting the e-cigarette industry - which is substantially owned by the tobacco 
industry - manipulate us and our governments by using the fear that without their products users will revert to tobacco, as leverage against appropriate regulatory action. This is a false choice, engineered by the industry, based on a pretense that there is no alternative to letting them keep millions addicted to nicotine.

From the start, CMAJ has called for a ban on flavourings in e-liquids, restrictions on e-cigarette advertising equivalent to those for tobacco products, and an effective standard for quality and safety to be imposed on every e-cigarette product sold. ${ }^{2,3} \mathrm{We}$ do so again now. In the United States, it has taken nationwide public concerns over the EVALI epidemic to prod government action at long last. Federal and state governments have proposed or implemented bans on flavoured e-liquids, which e-cigarette companies, predictably, are fighting in court. The US experience is showing us both the serious risks of inaction and part of the solution. Let us hope it is not too late for Canada's governments to learn.

\section{References}

1. Landman ST, Dhaliwal I, Mackenzie CA, et al. Life-threatening bronchiolitis related to electronic cigarette use in a Canadian youth. CMAJ 2019;191: E1321-31.

2. Stanbrook MB. Regulate e-cigarettes as drug-delivery devices. CMAJ 2013;185:1379.

3. Stanbrook MB. Electronic cigarettes and youth: a gateway that must be shut. CMAJ 2016;188:785

4. Outbreak of lung injury associated with the use of e-cigarette, or vaping, products. Atlanta: Centers for Disease Control and Prevention, Office on Smoking and Health, National Center for Chronic Disease Prevention and Health
Promotion; updated 2019 Oct. 31. Available: www.cdc.gov/tobacco/basic_ information/e-cigarettes/severe-lung-disease.html (accessed 2019 Nov. 3).

5. Severe lung illness related to vaping. Ottawa: Public Health Agency of Canada; modified 2019 Oct. 31. Available: www.canada.ca/en/public-health/services/ diseases/vaping-pulmonary-illness.html (accessed 2019 Nov. 3).

6. Kreiss K, Gomaa A, Kullman G, et al. Clinical bronchiolitis obliterans in workers at a microwave-popcorn plant. N Engl J Med 2002;347:330-8.

7. Sleiman M, Logue JM, Montesinos VN, et al. Emissions from electronic cigarettes: key parameters affecting the release of harmful chemicals. Environ Sci Technol 2016;50:9644-51.

8. AVA statement on President Trump's support for a FDA flavor ban [news release]. Stamford (CT): American Vaping Association; 2019 Sept. 11, 2019. Available: https://vaping.org/press-release/ava-statement-on-president -trumps-support-for-a-fda-flavor-ban (accessed 2019 Nov. 3).

9. Belluz J. Juul allegedly shipped 1 million contaminated vaping products. Vox Media 2019 Oct. 30. Available: www.vox.com/2019/10/30/20939978/juul -vaping-pods-lawsuit (accessed 2019 Nov. 3).

10. FDA warns JUUL Labs for marketing unauthorized modified risk tobacco products, including in outreach to youth [news release]. Rockville (MD): US Food and Drug Administration; 2019 Sept. 9. Available: www.fda.gov/news-events/ press-announcements/fda-warns-juul-labs-marketing-unauthorized-modified -risk-tobacco-products-including-outreach-youth (accessed 2019 Nov. 3).

11. Weeks $\mathrm{C}$. Health Canada considers allowing e-cigarette companies to promote harm-reduction benefits. Globe and Mail [Toronto]. Available: www.theglobe andmail.com/canada/article-health-canada-considers-allowing-e-cigarette -companies-to-promote-harm (accessed 2019 Nov. 3).

Competing interests: See www.cmaj.ca/site/misc/cmaj_staff.xhtml.

Affiliations: Deputy editor, CMAJ; Department of Medicine, University of Toronto, Ont.

Correspondence to: CMAJ editor, cmaj@cmajgroup.ca 